\title{
ÚNG DỤNG MÔ HİNH CẤU TRÚC TUYẾN TÍNH PHÂN TÍCH CÁC YÊU TỐ ẢNH HƯỞNG ĐẾN SỤ̉ HÀI LÒNG KHÁCH HÀNG TẠI CÁC NGÂN HÀNG THƯƠNG MẠI TỈNH QUẢNG NAM
}

\author{
USING THE STRUCTURAL EQUATION MODELLING \\ TO DETERMINE THE ANTECEDENTS OF CUSTOMER \\ SATISFACTION IN COMMERCIAL BANKS IN QUANG NAM \\ PROVINCE OF VIETNAM
}

\author{
Huỳnh Tấn Nguyên; Ngô Thị Tuyết Lan ${ }^{1}$
}

Ngày nhận bài: 25/12/2019 Ngày chấp nhận đăng: 17/02/2020 Ngày đăng: 05/08/2020

\section{Tóm tắt}

Nâng cao sự hài lòng khách hàng được cho là giải pháp giúp phát triển các hoạt động kinh doanh dịch vụ, trong đó có dịch vụ ngân hàng. Vì thế, nghiên cứu này nhằm mục đích nhận diện và đo lường các nhân tố tác động đến sự hài lòng khách hàng tại các ngân hàng thương mại ở Việt Nam. Để đạt được mục tiêu nghiên cứu, tác giả tiến hành khảo sát 461 khách hàng đã và đang giao dịch tại các ngân hàng thương mại và sử dụng mô hình cấu trúc tuyến tính (SEM) để kiểm định các giả thuyết nghiên cứu. Kết quả nghiên cứu cho thấy có bốn nhân tố tác động đến sự hài lòng khách hàng gồm: năng lực đáp ứng, cơ sở vật chất, giá dịch vụ, và bảo mật thông tin khách hàng. Dựa vào kết quả nghiên cứu, tác giả đề xuất một số hàm ý quản trị nhằm nâng cao sự hài lòng khách hàng. Bên cạnh các kết quả đạt được, nghiên cứu này còn một số hạn chế về phương pháp chọn mẫu, nên cần các nghiên cứu khác bổ sung.

Tù khoá: Sự hài lòng khách hàng, SEM, Ngân hàng thương mại, Mô hình cấu trúc tuyến tính.

\begin{abstract}
Improving customer satisfaction is one of key issues that leaders in banks are interested in nowadays. Hence, this study aimed to identify and measure factors affecting customer satisfaction in commercial banks via both qualitative and quantitative approaches. To do so, the questionnaire was designed to officially survey 461 customers transacting at commercial banks in Quang Nam province, Vietnam. The study then used the Structural Equation Modelling (SEM) to test the research proposed model. The results showed that there are four factors affecting customer satisfaction, including: responsiveness, facility, service price, and secrecy. Based on the findings, the research proposed some managerial implications to enhance customer satisfaction. However, the study had some limitations, so more studies with alternative methods should be conducted to confirm the results of this study for better policies.
\end{abstract}

Keywords: Customer satisfaction, Structural Equation Model (SEM), Commercial banks.

${ }^{1}$ Trường Đại học Công nghệ Đồng Nai 


\section{Giới thiệu}

$\mathrm{Xu}$ thế của nền kinh tế thế giới là toàn cầu hóa, nhờ đó đã tạo động lực cho các ngành kinh tế cạnh tranh và phát triển, trong đó có ngành ngân hàng. Đối với ngành tài chính ngân hàng, toàn cầu hóa và hội nhập kinh tế quốc tế tạo ra động lực và điều kiện để nâng cao hiệu quả kinh doanh (Lê Thị Thanh Giang, 2016). Bên cạnh đó, hội nhập kinh tế còn mở rộng cơ hội trao đổi hợp tác giữa các ngân hàng thương mại. Đồng thời, các ngân hàng Việt Nam có thể tranh thủ các cơ hội để huy động vốn, cải thiện công nghệ, cơ chế quản lý để có thể tồn tại ở Việt Nam và vươn ra thị trường nước ngoài (Trần Thu Hằng, 2017). Tuy nhiên, hiện nay các ngân hàng thương mại đang gặp phải nhiều khó khăn, chịu sự cạnh tranh rất khốc liệt, đặc biệt với ngân hàng nước ngoài.

Trong quá trình hội nhập, Việt Nam sẽ phải chấp nhận sự gia nhập mạnh của các ngân hàng nước ngoài có tiềm lực vốn lớn, có công nghệ tiên tiến, và có khả năng quản trị tốt. Thực tế đó dẫn đến sự cạnh tranh trong lĩnh vực ngân hàng khốc liệt hơn bao giờ hết. Để giành được lợi thế trong quá trình hội nhập, các ngân hàng Việt Nam cần nâng cao năng lực quản trị và năng lực cạnh tranh trong lúc Nhà nước đang dần bỏ các lợi thế và ưu đãi cho ngân hàng trong nước (Trần Trọng Khuê và Lê Thúy Kiều, 2017).

Mục tiêu của nghiên cứu này là: (1) Xác định và đo lường mức độ tác động của các yếu tố đến sự hài lòng khách hàng tại các ngân hàng thương mại, (2) Đề xuất một số hàm ý quản trị nhằm nâng cao sự hài lòng khách hàng tại các ngân hàng thương mại.

\section{Cơ sở lý thuyết và mô hình nghiên cứu}

\subsection{Sụ hài lòng của khách hàng}

Theo Bhat, Darzi, và Parrey (2018) "Sự hài lòng của khách hàng (customer satisfaction) là một cảm giác khi khách hàng được trải nghiệm sản phẩm và dịch vụ đáp ứng tốt nhu cầu của họ". Lone, Aldawood, và Bhat (2017) thì cho rằng: "Sự hài lòng của khách hàng là sự đánh giá của khách hàng về một sản phẩm và dịch vụ mà khách hàng mong đợi”. Ong, Nguyen, và Syed Alwi (2017) định nghĩa "Sự hài lòng như là một cảm giác hài lòng hoặc thất vọng của một người bằng kết quả của việc so sánh thực tế nhận được của sản phẩm (hay kết quả) trong mối liên hệ với những mong đợi của họ".

Đa số các nhà quản trị marketing cho rằng sự hài lòng khách hàng là thước đo sự hiệu quả của hoạt động quản trị trong doanh nghiệp. Pérez và Del Bosque (2015) cho rằng, nếu khách hàng hài lòng về sản phẩm và dịch vụ mà doanh nghiệp cung cấp thì họ có xu hướng tiếp tục mua hàng, và giới thiệu cho nhiều người khác. Do đó, nếu doanh nghiệp có thể khiến khách hàng cảm thấy tin tưởng và hài lòng khi sử dụng sản phẩm thì đây chính là điều kiện cần thiết để doanh nghiệp nâng cao lợi nhuận và phát triển bền vững.

Anouze (2019) thì cho rằng: "Sự hài lòng là trạng thái cảm giác của một người sau khi tiêu dùng sản phẩm và dịch vụ". Còn theo Sayani (2015) thì cho rằng sự hài lòng của khách hàng là việc so sánh giữa việc mong muốn của người tiêu dùng với cảm giác thực nhận sau khi tiêu dùng. Mức độ hài lòng phụ thuộc vào khoảng cách giữa sự mong đợi của khách hàng và giá trị thực sau khi tiêu dùng. Nếu giá trị thực sau khi tiêu dùng thấp hơn kỳ vọng thì khách hàng sẽ không hài lòng.

\subsection{Phát triển giả thuyết nghiên cứu}

2.2.1. Mối quan hệ giữa sụ hài lòng với "năng lục đáp ứng"

Năng lực đáp ứng (responsiveness) liên quan đến thời gian giải quyết hồ sơ của khách hàng, và sự đáp ứng các nhu cầu của khách hàng nhanh chóng. Nghiên cứu của Koraus, Stefko, và Dobrovic (2016) và Shahrinaz et al. (2017) cho thấy có 5 nhóm yếu tố chính tác động đến sự hài lòng khách hàng: năng lực đáp ứng, tính minh bạch, cơ chế ngân hàng, sự phục vụ, năng lực cạnh tranh. Cũng theo nhóm nghiên cứu, năng lực đáp ứng liên quan đến thời gian giao dịch với khách hàng, và liên quan đến quy trình nghiệp vụ tại Ngân hàng thương mại. Nghiên 
cứu của Yen, Hui, Jais, và Rasiah (2018) về ảnh hưởng của dịch vụ ngân hàng điện tử đến sự hài lòng khách hàng cũng cho thấy năng lực đáp ứng của $\mathrm{Ngân}$ hàng đã làm khách hàng cảm thấy hài lòng hơn khi giao dịch. Trong nghiên cứu này nhóm tác giả đã tính toán chỉ số hài lòng trong trường hợp này đạt 4,05 . Còn theo Sayani (2015) thì cho rằng năng lực đáp ứng có tác động lớn đến sự hài lòng của khách hàng, nếu năng lực đáp ứng được thực hiện tốt sẽ làm giảm thời gian giao dịch với ngân hàng lên đến $90 \%$. Hơn nữa, nghiên cứu của Hult, Morgeson, Morgan, Mithas, và Fornell (2017) về ảnh hưởng của năng lực đáp ứng đến sự hài lòng khách hàng cũng có kết luận tương tự. Theo kết quả nghiên cứu, năng lực đáp ứng của ngân hàng liên quan đến việc hồ trợ cho khách hàng những thông tin cần thiết.

Kế thừa kết quả từ các kết quả nghiên cứu trên, giả thuyết nghiên cứu được đề xuất như sau:

Giả thuyết $\mathrm{H}_{1}$ : "Năng lực đáp ứng" tác động cùng chiều đến sự hài lòng khách hàng.

2.2.2. Mối quan hệ giũa "co" sở vật chất" với sụ hài lòng của khách hàng

Cơ sở vật chất (facility) trong ngân hàng liên quan đến các phương tiện hữu hình phục vụ giao dịch: trụ sở, bàn ghế, cơ sở vật chất, v.v. Theo Yen et al. (2018) trong 5 nhóm nhân tố tác động đến sự hài lòng khách hàng thì yếu tố "cơ sở vật chất" có tác động nhiều nhất (hệ số bằng 0,067 , $\mathrm{P}=0,008)$. Theo Mohan et al. (2016) thì cơ sở vật chất phục vụ khách hàng bao gồm máy móc thiết bị, đường truyền internet, máy rút tiền tự động, trụ sở giao dịch, và các tài liệu hướng dẫn cung cấp thông tin. Còn theo Hult et al. (2017) thì cho rằng cơ sở vật chất là yếu tố đầu tiên, quan trọng nhất tác động đến sự hài lòng khách hàng. Từ đó, nhóm nghiên cứu đề xuất các giải pháp cải thiện và đầu tư cơ sở vật chất để phục vụ nhu cầu khách hàng. Nghiên cứu của Trần Trọng Khuê và Lê Thúy Kiều (2017) cho thấy yếu tố cơ sở vật chất rất quan trọng đối với các khách hàng đến từ Mỹ và Châu Ầu. Nghiên cứu của Lê Thị Thanh Giang (2016) cũng cho kết quả tương tự.
Kế thừa kết quả của các nghiên cứu trên, tác giả đề xuất giả thuyết thứ 2 trong nghiên cứu này là:

Giả thuyết $\mathbf{H}_{2}$ : Yếu tố "Cơ sở vật chất" tác động cùng chiều đến sự hài lòng khách hàng.

2.2.3. Mối quan hệ giữa "tính thuận lợi" và sụ hài lòng khách hàng

Tính thuận lợi (convenience) trong dịch vụ ngân hàng sẽ ảnh hưởng đến sự hài lòng của khách hàng, nhờ tính thuận lợi giúp khách hàng giao dịch thuận tiện, giảm thời gian giao dịch (Belás, Korauš, Kombo, \& Korauš, 2016; Mohan et al., 2016). Theo Singhal, Bala, và Sarawgi (2018) thì tính thuận lợi trong hoạt động Ngân hàng liên quan đến việc xử lý các vấn đề của khách hàng một cách nhanh chóng và chính xác, từ đó giúp nâng cao sự hài lòng khách hàng. Mặt khác, nghiên cứu của Hoàng Phương Dũng (2018) cũng cho thấy tính thuận tiện không những nâng cao sự hài lòng khách hàng mà còn giúp ngân hàng nâng cao uy tín và nâng cao thương hiệu. Một số nghiên cứu khác cho thấy tính thuận lợi trong hoạt động của ngân hàng liên quan đến quy trình thủ tục cung cấp dịch vụ (Janahi \& Al Mubarak, 2017), liên quan đến thời gian giải quyết yêu cầu của khách hàng (Hammoud, Bizri, \& El Baba, 2018), và liên quan đến mạng lưới giao dịch (Firdous \& Farooqi, 2017).

Kế thừa kết quả từ các nghiên cứu trước, giả thuyết thứ 3 được đề xuất như sau:

Giả thuyết $\mathbf{H}_{3}$ : Yếu tố "Tính thuận lợi" tác động cùng chiều đến sự hài lòng khách hàng.

2.2.4. Mối quan hệ giũa "giá dịch vụ" và sụ hài lòng khách hàng

Cũng như các lĩnh vực kinh doanh khác, đối với ngân hàng giá dịch vụ (service price) tác động lớn tới tâm lý và hành vi khách hàng. Giá dịch vụ liên quan tới lãi suất tiền gửi, lãi suất tiền vay, và các loại phí khác có liên quan. Theo Jalali, Ferreira, Ferreira, và Meidutè (2016) thì giá dịch vụ có tác động cùng chiều tới sự hài lòng của khách hàng. Thông qua mô hình SEM, nghiên cứu đã cho thấy giá dịch vụ có tác 
động lớn nhất đến sự hài lòng của khách hàng (hệ số bằng $0,876, \mathrm{P}=0,0067$ ). Thông qua mô hình hồi quy bội, nghiên cứu của Raza, Jawaid, và Hassan (2015) cũng cho kết quả tương tự. Trong nghiên cứu của mình, Trần Dục Thức và Phạm Thị Lan Hương (2017) cũng đề xuất các giải pháp nhằm cải thiện giá dịch vụ ngân hàng, nhằm nâng cao sự hài lòng của khách hàng. Giải pháp này tương tự với đề xuất của Belás et al. (2016) khi nghiên cứu về sự hài lòng của khách hàng tại các ngân hàng thương mại Slovakia.

Kế thừa các kết quả nghiên cứu trước, tác giả đề xuất giả thuyết thứ 4 là:

Giả thuyết $\mathbf{H}_{4}$ : Yếu tố "Giá dịch vụ" tác động cùng chiều đến sự hài lòng khách hàng.

\subsubsection{Mối quan hệ giũa "bảo mật thông tin"} và sụ hài lòng khách hàng

Công nghệ hiện đại làm cho dịch vụ ngân hàng trở nên thuận tiện hơn bao giờ hết. Do đó, yếu tố bảo mật thông tin (secrecy) được khách hàng rất quan tâm. Bảo mật thông tin trong ngân hàng quyết định việc khách hàng có trung thành không (Hoàng Phương Dũng, 2018; Singhal et al., 2018), quyết định đến chất lượng dịch vụ để thu hút khách hàng (Hill \& Alexander, 2017; Janahi \& Al Mubarak, 2017). Theo Hammoud et al. (2018) thì nâng cao bảo mật trong hoạt động ngân hàng cần nhiều chi phí, nhưng sẽ khiến khách hàng hài lòng hơn. Nghiên cứu của Firdous và Farooqi (2017) đề xuất đầu tư để đảm bảo tính bảo mật và tạo sự an tâm cho khách hàng. Nghiên cứu của Ong et al. (2017) cũng có đề xuất tương tự. Nhiều nghiên cứu khác cho thấy yếu tố bảo mật thông tin liên quan đến bảo mật thông tin khách hàng (Raza et al., 2015), tạo sự an tâm và tin cậy cho khách hàng (Amin, 2016).

Kế thừa kết quả của những nghiên cứu trước, giả thuyết thứ 5 của nghiên cứu này được đề xuất như sau:

Giả thuyết $\mathbf{H}_{5}$ : Yếu tố "Bảo mật thông tin" tác động cùng chiều đến sự hài lòng khách hàng.

\subsection{Mô hình nghiên cứu đề nghị}

Dựa trên việc kế thừa và tổng hợp các kết quả nghiên cứu trước, đề tài đề xuất mô hình nghiên cứu và các giả thuyết nghiên cứu như Hình 1.

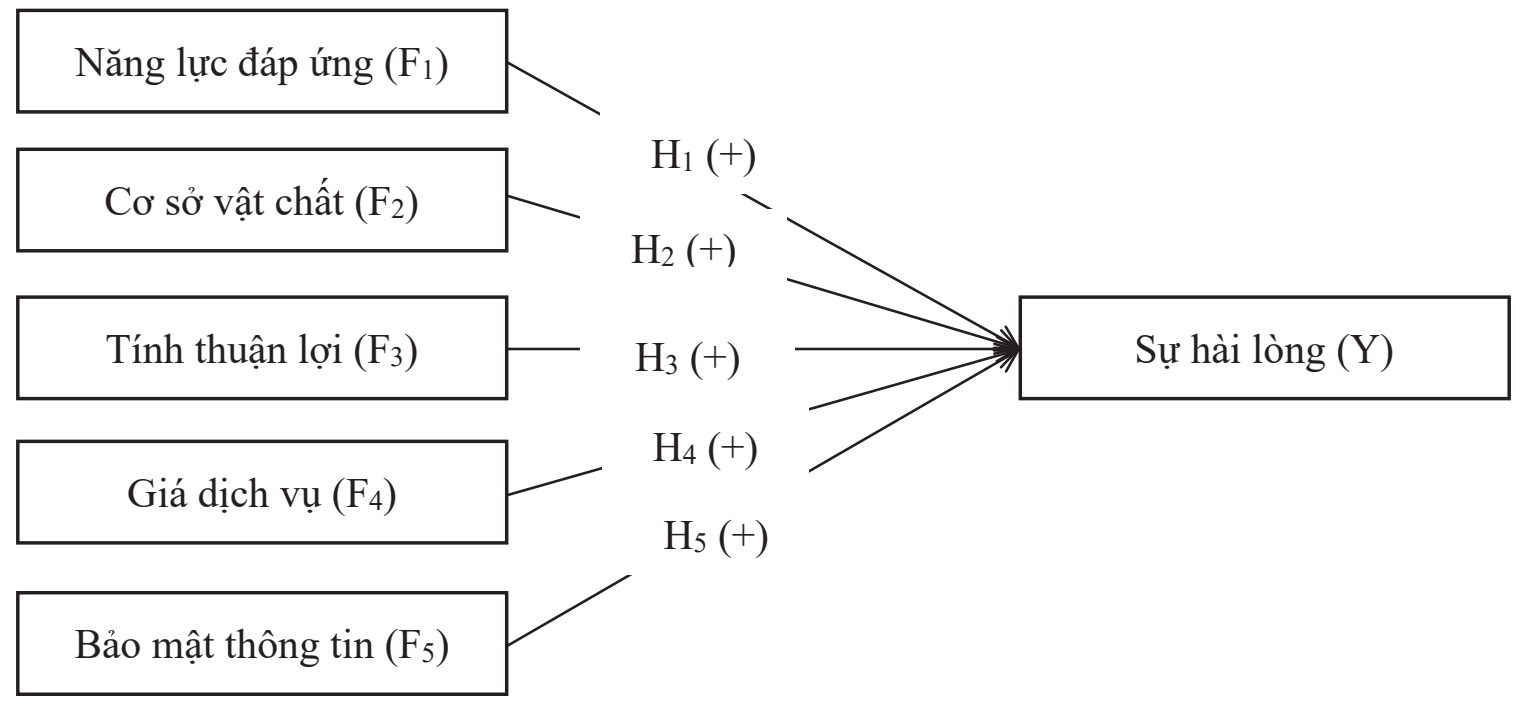

\section{Hình 1. Mô hình nghiên cứu đề nghị}

Nguồn: Đề xuất của tác giả

\section{Phương pháp nghiên cứu}

\subsection{Thiết kế nghiên cứu}

Dựa vào mục tiêu nghiên cứu, tác giả đã tiến hành tổng quan tài liệu tham khảo liên quan đến sự hài lòng khách hàng và hình thành mô hình nghiên cứu ban đầu. Để kiểm định mô hình nghiên cứu, tác giả đã thực hiện nghiên cứu theo 2 bước như sau: 
Bảng 1. Thiết kế nghiên cứu

\begin{tabular}{|c|c|c|c|}
\hline $\begin{array}{l}\text { Phương } \\
\text { pháp }\end{array}$ & Mẫu khảo sát & Mục tiêu & $\begin{array}{l}\text { Thò̀i gian } \\
\text { thụ̣c hiện }\end{array}$ \\
\hline \multirow{3}{*}{$\begin{array}{l}\text { Nghiên } \\
\text { cứu định } \\
\text { tính: Kỹ } \\
\text { thuật } \\
\text { phỏng } \\
\text { vấn sâu }\end{array}$} & $\begin{array}{l}\text { Ban Giám đốc: } 2 \text { người (gồm } 1 \text { Phó } \\
\text { giám đốc và } 1 \text { giám đốc). }\end{array}$ & $\begin{array}{l}\text { Tìm hiểu các nhân tố tác động } \\
\text { đến sự hài lòng của khách hàng, } \\
\text { và kiểm tra sự phù hợp của lý } \\
\text { thuyết. }\end{array}$ & \multirow[t]{3}{*}{$\begin{array}{l}\text { Từ tháng } \\
\text { 4/2018 } \\
\text { đến tháng } \\
\text { 6/2018 }\end{array}$} \\
\hline & $\begin{array}{l}\text { Chuyên gia: } 3 \text { người ( } 1 \text { người đang } \\
\text { công tác tại Ngân hàng Nhà nước tỉnh } \\
\text { Quảng Nam, } 1 \text { người là Giảng viên } \\
\text { Khoa Ngân hàng của Đại học Quảng } \\
\text { Nam, } 1 \text { người là Giám đốc công ty } \\
\text { chứng khoán SCV Quảng Nam). }\end{array}$ & $\begin{array}{l}\text { Kiểm tra sự hợp lý của mô hình } \\
\text { nghiên cứu ban đầu. }\end{array}$ & \\
\hline & $\begin{array}{l}\text { Khách hàng: } 9 \text { người đang giao dịch } \\
\text { tại } 9 \text { ngân hàng thương mại trên địa } \\
\text { bàn tỉnh Quảng Nam. }\end{array}$ & $\begin{array}{l}\text { - Thăm dò cảm nhận của khách } \\
\text { hàng về sự hài lòng khi giao } \\
\text { dịch tại ngân hàng. } \\
\text { - Điều chỉnh lại các mục hỏi } \\
\text { trong bảng khảo sát chính thức. }\end{array}$ & \\
\hline $\begin{array}{l}\text { Nghiên } \\
\text { cứu định } \\
\text { lượng }\end{array}$ & $\begin{array}{l}\text { Khách hàng đã và đang giao dịch tại } \\
\text { các ngân hàng: } 461 \text { người. }\end{array}$ & $\begin{array}{l}\text { - Kiểm định mô hình nghiên } \\
\text { cứu ban đầu. } \\
\text { - Đo lường tác động của các } \\
\text { nhân tố tác động tới sự hài lòng } \\
\text { khách hàng. }\end{array}$ & $\begin{array}{l}\text { Từ tháng } \\
\text { 7/2018 } \\
\text { tới tháng } \\
\text { 9/2018 }\end{array}$ \\
\hline
\end{tabular}

Nguồn: Đề xuất của tác giả

\subsection{Quy trình xây dụng thang đo}

Quy trình xây dựng thang đo được thực hiện như sau:

- Thông qua việc tổng hợp từ các kết quả nghiên cứu trước, tác giả kế thừa các mục hỏi để sử dụng cho nghiên cứu này.

- Đối với các mục hỏi bằng tiếng $A n h$, tác giả tiến hành xây dựng phiên bản tiếng Việt.
- Bảng hỏi bằng tiếng Việt được đưa cho các khách hàng đọc, đánh giá, nhận xét để làm rõ các ý nghĩa của các mục hỏi, và đảm bảo không có sự hiểu nhầm về ngữ nghĩa.

- Bảng hỏi chính thức được gửi tới 500 khách hàng đã và đang giao dịch tại các ngân hàng thương mại tỉnh Quảng Nam.

Danh sách các biến và nguồn gốc thang đo được trình bày trong bảng dưới đây.

\section{Bảng 2. Danh sách và nguồn gốc thang đo}

\begin{tabular}{|l|l|}
\hline \multicolumn{1}{|c|}{ Thang đo } & \multicolumn{1}{c|}{ Nguồn tham khảo } \\
\hline Năng lực đáp ứng & $\begin{array}{l}\text { Áp dụng có điều chỉnh thang đo của Colm, Ordanini, vàarasuraman } \\
\text { (2017), Ling, Fern, Boon, và Huat (2016a) }\end{array}$ \\
\hline Cơ sở vật chất & $\begin{array}{l}\text { Áp dụng có điều chỉnh thang đo của Ling, Fern, Boon, và Huat (2016b), } \\
\text { Rajagopal và Mahajan (2019) }\end{array}$ \\
\hline Tính thuận lợi & $\begin{array}{l}\text { Áp dụng có điều chỉnh thang đo của Dsouza, Subhash, và Weiermair } \\
\text { (2018), Belás, Chocholáková, và Gabčová (2015) }\end{array}$ \\
\hline
\end{tabular}




\begin{tabular}{|l|l|}
\hline \multicolumn{1}{|c|}{ Thang đo } & \multicolumn{1}{c|}{ Nguồn tham khảo } \\
\hline Giá dịch vụ & $\begin{array}{l}\text { Áp dụng có điều chỉnh thang đo của Saleem, Zahra, Ahmad, và Ismail } \\
\text { (2016), Darzi Mushtaq (2018) }\end{array}$ \\
\hline Bảo mật thông tin & $\begin{array}{l}\text { Áp dụng có điều chỉnh thang đo của Adeel, Ali, và Pengcheng (2018), } \\
\text { Youssef, Anadol, và Zahrani (2017) }\end{array}$ \\
\hline Sự hài lòng & $\begin{array}{l}\text { Áp dụng có điều chỉnh thang đo của Larivière et al. (2016), Tadic, Aleksic, } \\
\text { Mimovic, Puskaric, và Misita (2018) }\end{array}$ \\
\hline
\end{tabular}

Nguồn: Tổng hợp của tác giả

\subsection{Chọn mẫu nghiên cứu}

Hair, Black, Babin, Anderson và Tatham (2006) cho rằng để sử dụng $\mathrm{EFA}$, kích thước mẫu tối thiểu là 50 , tốt hơn là 100 và tỉ lệ quan sát/biến đo lường là $5: 1$, nghĩa là 1 biến đo lường cần tối thiểu là 5 quan sát, tốt nhất là 10:1 trở lên. Nghiên cứu này bao gồm 33 biến quan sát, cho nên kích thước mẫu khảo sát ít nhất là 330 khách hàng. Trong nghiên cứu này, tác giả tiến hành khảo sát 500 khách hàng bằng hình thức phát phiếu khảo sát trực tiếp và khảo sát online thông qua hệ thống googleform tại 9 ngân hàng thương mại trên địa bàn Quảng Nam, sau khi làm sạch số liệu kết quả thu về 461 phiếu khảo sát hợp lệ để sử dụng cho nghiên cứu chính thức (Bảng 3).

Bảng 3. Kết quả thu hồi phiếu khảo sát

\begin{tabular}{|l|c|c|}
\hline \multicolumn{1}{|c|}{ Tên ngân hàng } & $\begin{array}{c}\text { Số } \\
\text { lượng }\end{array}$ & \% \\
\hline Ngân hàng Ngoại thương & 39 & 8,46 \\
\hline Ngân hàng Đầu tư \& Phát triển & 34 & 7,38 \\
\hline Ngân hàng MHB & 44 & 9,54 \\
\hline Ngân hàng Đông Á & 37 & 8,03 \\
\hline Ngân hàng Kỹ thương & 53 & 11,5 \\
\hline Ngân hàng Hàng hải & 61 & 13,23 \\
\hline Ngân hàng Á Châu & 73 & 15,84 \\
\hline $\begin{array}{l}\text { Ngân hàng Việt Nam Thịnh } \\
\text { Vượng }\end{array}$ & 33 & 7,16 \\
\hline Ngân hàng Bưu điện Liên Việt & 87 & 18,87 \\
\hline \multicolumn{1}{|c|}{ Tổng cộng } & $\mathbf{4 6 1}$ & $\mathbf{1 0 0}$ \\
\hline
\end{tabular}

Nguồn: Tổng hợp tù số liệu khảo sát

\subsection{Phương pháp phân tích dũ liệu}

Dữ liệu sau khi nhập vào máy tính, được phân tích theo các bước sau:

Thứ nhất: Thực hiện thống kê mô tả, tính số trung bình, tính tần số, tần suất, và so sánh sự khác biệt giữa các nhóm kiểm soát.

Thư 2: Đánh giá độ tin cậy của thang đo thông qua hệ số Cronbach's Alpha.

Độ tin cậy của thang đo được đánh giá thông qua hệ số Cronbach's alpha và hệ số tương quan biến tổng (item-total correlation). Nó giúp đo lường mức độ chặt chẽ mà các biến quan sát trong thang đo tương quan với nhau (Hair Jr, Hult, Ringle, \& Sarstedt, 2016). Theo Hair et al. (2006) thì Cronbach's alpha từ 0,6 trở lên là có thể sử dụng được trong trường hợp khái niệm thang đo lường là mới hoặc mới đối với người trả lời trong bối cảnh nghiên cứu. Trong nghiên cứu này, hầu hết các thang đo đều được kế thừa từ các nghiên cứu trước, vì thế những thang đo có hệ số Cronbach's alpha đạt giá trị từ 0,7 trở lên mới được lựa chọn. Mặt khác, thang đo nào có hệ số tương quan biến tổng nhỏ hơn 0,3 bị coi là biến rác và loại khỏi mô hình nghiên cứu (Fabrigar \& Wegener, 2011).

Thư 3: Sử dụng kỹ thuật phân tích nhân tố khám phá (EFA).

Các nghiên cứu cho rằng hệ số tải nhân tố (factor loading) phải lớn hơn 0,5 thì thang đo đạt giá trị hội tụ (Hair et al., 2006) và hệ số tải của nhân tố này phải lớn hơn hệ số tải của nhân tố khác là 0,3 thì đạt giá trị phân biệt (Fabrigar \& Wegener, 2011). Do đó, trong 
nghiên cứu này giá trị hệ số tải nhân tố nhỏ hơn 0,5 thì biến tương ứng bị loại. Phương pháp trích nhân tố được sử dụng là phương pháp PC (principal components) và phương pháp xoay nhân tố là phương pháp Varimax with Kaiser Normalization. Điểm dừng trích khi có "Initial Eigenvalues" $>1$.

Thư 4: Phân tích nhân tố khẳng định (CFA).

Sau khi phân tích nhân tố, các biến quan sát sẽ được đưa vào mô hình CFA. Các tiêu chí để mô hình CFA đạt yêu cầu là: chỉ số Chi-square có ý nghĩa thống kê $(\mathrm{P}<5 \%)$, Chi-square/ df nhỏ hơn 3, CFI lớn hơn 0.9, RMSEA nhỏ hơn 0,08 (Chatfield, 2018; Silverman, 2018; Varmuza, 2018). Sau khi mô hình CFA đạt yêu cầu, nếu Độ tin cậy tổng hợp (CR) lớn hơn 0,7 và Phương sai trích trung bình (AVE) lớn hơn 0,5 thì thang đo đáng tin cậy, có thể sử dụng cho phân tích SEM (Hair et al., 2006).

Thư 5: Kiểm định mô hình nghiên cứu thông qua mô hình cấu trúc tuyến tính (SEM).

Sau khi CFA, nghiên cứu sử dụng mô hình cấu trúc tuyến tính (SEM) được sử dụng để kiểm định các mối quan hệ trong mô hình nghiên cứu. Cũng giống như CFA, mô hình SEM đạt yêu cầu nếu chỉ số Chi-square có ý nghĩa thống kê $(\mathrm{P}<5 \%)$, Chi-square/df nhỏ hơn 3, CFI lớn hơn 0,9, RMSEA nhỏ hơn 0,08 (Chatfield, 2018; Varmuza, 2018).

\section{Kết quả nghiên cứu và thảo luận}

\section{1. Đánh giá độ tin cậy của thang đo}

Kết quả phân tích độ tin cậy của thang đo của các thành phần đo lường sự hài lòng của khách hàng tại các ngân hàng thương mại được thể hiện tại bảng 4 dưới đây:
Bảng 4. Kết quả kiểm định Cronbach's Alpha

\begin{tabular}{|l|c|}
\hline \multicolumn{1}{|c|}{ Thang đo } & Cronbach's Alpha \\
\hline Tính thuận lợi & 0,815 \\
\hline Cơ sở vật chất & 0,880 \\
\hline Giá dịch vụ & 0,810 \\
\hline Bảo mật thông tin & 0,610 \\
\hline Năng lực đáp ứng & 0,871 \\
\hline Sự hài lòng & 0,862 \\
\hline
\end{tabular}

Nguồn: Tính toán tì̀ số liệu khảo sát

Tất cả các biến quan sát đều đạt yêu cầu, ngoại trừ biến "BM_3". Do đó, biến này bị loại khỏi các phân tích tiếp theo.

\subsection{Phân tích nhân tố khám phá (EFA)}

\subsubsection{Phân tích EFA cho các biến độc lập}

Kết quả phân tích EFA cho thấy hệ số KMO bằng 0,946 (lớn hơn 0,5 ) và kiểm định Bartlett có ý nghĩa thông kê ở mức nhỏ hơn $5 \%$. Cho thấy số liệu phù hợp với phân tích nhân tố khám phá.

\section{KMO and Bartlett's Test}

\begin{tabular}{|ll|r|}
\hline \multicolumn{2}{|l|}{ Kaiser-Meyer-Olkin Measure of } & 0,946 \\
Sampling Adequacy. & \\
Bartlett's $\quad$ Approx. Chi-Square & 643638 \\
Test of & df & 351 \\
Sphericity & Sig. & 0,000 \\
\hline
\end{tabular}

Theo kết quả phân tích, các biến nghiên cứu trích được 5 nhân tố như mô hình ban đầu, tổng phương sai trích bằng $61,05 \%$ (cao hơn $50 \%$ ). Giá trị Eigen của nhân tố đều lớn hơn 1 . Theo kết quả EFA thì chỉ có các biến "VC_7" bị loại vì có hệ số tải nhân tố nhỏ hơn 0,5 . Do đó, biến này sẽ bị loại trong các phân tích tiếp theo.

Bảng 5. Kết quả phân tích nhân tố cho biến độc lập

\begin{tabular}{|c|c|c|c|c|c|}
\hline \multirow{2}{*}{$\begin{array}{c}\text { Biến } \\
\text { quan sát }\end{array}$} & \multicolumn{5}{|c|}{ Nhân tố } \\
\hline & $\begin{array}{c}\text { NĂNG LỤC } \\
\text { ĐÁP ÚNG }\end{array}$ & $\begin{array}{c}\text { CO' SỎ } \\
\text { VÂT CHẤT }\end{array}$ & \begin{tabular}{|c|} 
TÍNH \\
THUÂN LỢI
\end{tabular} & $\begin{array}{c}\text { GIÁ } \\
\text { DİCH VỤ }\end{array}$ & $\begin{array}{c}\text { BẢO MẬT } \\
\text { THÔNG TIN }\end{array}$ \\
\hline DA_2 & 0,758604 & & & & \\
\hline DA_1 & 0,749303 & & & & \\
\hline DA_4 & 0,694737 & & & & \\
\hline
\end{tabular}




\begin{tabular}{|c|c|c|c|c|c|}
\hline \multirow{2}{*}{$\begin{array}{c}\text { Biến } \\
\text { quan sát }\end{array}$} & \multicolumn{5}{|c|}{ Nhân tố } \\
\hline & $\begin{array}{l}\text { NĂNG LỰC } \\
\text { ĐÁP ÚNG }\end{array}$ & $\begin{array}{c}\text { CO' SỎ' } \\
\text { VẠT CHẤT }\end{array}$ & \begin{tabular}{|c|} 
TÍNH \\
THUẬA LỌI
\end{tabular} & \begin{tabular}{|c|} 
GIÁ \\
DỊCH VỤ
\end{tabular} & $\begin{array}{c}\text { BẢO MẬT } \\
\text { THÔNG TIN }\end{array}$ \\
\hline DA_3 & 0,693801 & & & & \\
\hline DA_5 & 0,616542 & & & & \\
\hline DA_6 & 0,575917 & & & & \\
\hline $\mathrm{VC} \_1$ & & 0,701831 & & & \\
\hline $\mathrm{VC} \_2$ & & 0,636501 & & & \\
\hline VC_4 & & 0,611448 & & & \\
\hline $\mathrm{VC} \_3$ & & 0,607959 & & & \\
\hline $\mathrm{VC} \_5$ & & 0,575386 & & & \\
\hline VC_6 & & 0,519395 & & & \\
\hline $\mathrm{VC} \_7$ & & & & & \\
\hline TL_1 & & & 0,694108 & & \\
\hline TL_2 & & & 0,685356 & & \\
\hline TL_3 & & & 0,679423 & & \\
\hline TL_4 & & & 0,630919 & & \\
\hline TL_6 & & & 0,591846 & & \\
\hline TL_5 & & & 0,578324 & & \\
\hline GDV_1 & & & & 0,79955 & \\
\hline DGV_2 & & & & 0,69873 & \\
\hline DGV_3 & & & & 0,67043 & \\
\hline DGV_4 & & & & 0,53464 & \\
\hline BM_4 & & & & & 0,737432 \\
\hline BM_1 & & & & & 0,654789 \\
\hline BM_2 & & & & & 0,551677 \\
\hline BM_5 & & & & & 0,535308 \\
\hline Eigenvalues & 11,1556 & 1,7071 & 1,4881 & 1,1142 & 1,0194 \\
\hline \% phương sai trích & 41,3169 & 6,3227 & 5,5114 & 4,1267 & 3,7754 \\
\hline \% phương sai cộng dồn & 41,3169 & 47,6395 & 53,151 & 57,2777 & 61,0531 \\
\hline
\end{tabular}

\subsubsection{Phân tích EFA cho biến phục thuộc}

Khái niệm "Sự hài lòng" trong nghiên cứu này được cấu thành từ 5 biến thành phần. Kết quả EFA cho thấy giá trị KMO bằng 0,859 (lớn hơn $50 \%$ ) và kiểm định Bartlett có ý nghĩa thống kê ở mức nhỏ hơn 5\% nên số liệu khảo sát phù hợp cho phân tích nhân tố khám phá.

\section{KMO and Bartlett's Test}

\begin{tabular}{|ll|r|}
\hline Kaiser-Meyer-Olkin Measure of & 0,859 \\
Sampling Adequacy. & \\
Bartlett's Approx. Chi-Square & 982,507 \\
Test of & df & 10 \\
Sphericity & Sig. & 0,000 \\
\hline
\end{tabular}

Kết quả EFA cho thấy biến quan sát trong thang đo "sự hài lòng" đều đạt yêu cầu. Do đó được sử dụng trong các phân tích tiếp theo. 
Bảng 6. Kết quả EFA của thang đo "Sự hài lòng"

\begin{tabular}{|l|r|}
\hline & Sự hài lòng \\
\hline SHL_3 & 0,847 \\
SHL_4 & 0,809 \\
SHL_2 & 0,798 \\
SHL_5 & 0,786 \\
SHL_1 & 0,772 \\
Egenvalue & $\mathbf{3 , 2 2 1}$ \\
Tổng phương sai trích & $\mathbf{6 4 , 4 4 2}$ \\
\hline
\end{tabular}

Nguồn: Tính toán tù số liệu khảo sát

\subsection{Phân tích nhân tố khẳng định (CFA)}

Kết quả CFA được đánh giá thông qua 3 chỉ tiêu: Tính đơn hướng, giá trị hội tụ, hệ số tổng hợp và phương sai trích bình quân.

Tính đơn hướng: Kết quả CFA cho thấy rằng mô hình này phù hợp với dữ liệu thị trường: Chi-bình phương $=927,132$ với bậc tự do $\mathrm{df}=332 ;$ giá trị $\mathrm{p}=0,000 ; \mathrm{CMIN} / \mathrm{df}=2,793$; $\mathrm{GFI}=0,875, \mathrm{TLI}=0,9 ; \mathrm{CFI}=0,912$; $\mathrm{RMSEA}$ =0,062 (Hình 2).

Giá trị hội tụ: Hình 2 cho thấy các trọng số CFA đều đạt tiêu chuẩn cho phép lớn hơn 0,50 (thấp nhất là 0,65 và cao nhất là 0,91 ) và có ý nghĩa thống kê ở mức 0,05 .

\section{Bảng 7. Kết quả phân tích CFA}

\begin{tabular}{|l|c|c|r|r|c|}
\hline \multicolumn{1}{|c|}{ Thang đo } & $\begin{array}{c}\text { Ký } \\
\text { hiệu }\end{array}$ & $\begin{array}{c}\text { Số } \\
\text { biến }\end{array}$ & $\begin{array}{c}\text { Độ tin cậy } \\
\text { tổng hộp (CR) }\end{array}$ & $\begin{array}{c}\text { Phương sai trích } \\
\text { trung bình (AVE) }\end{array}$ & Kết luận \\
\hline Năng lực đáp ứng & $\mathrm{F}_{1}$ & 6 & 0,865543 & 0,518827 & Đạt yêu cầu \\
\hline Cơ sở vật chất & $\mathrm{F}_{2}$ & 5 & 0,849552 & 0,531231 & Đạt yêu cầu \\
\hline Tính thuận lợi & $\mathrm{F}_{3}$ & 6 & 0,816107 & 0,525269 & Đạt yêu cầu \\
\hline Giá dịch vụ & $\mathrm{F}_{4}$ & 4 & 0,797496 & 0,496602 & Đạt yêu cầu \\
\hline Bảo mật thông tin & $\mathrm{F}_{5}$ & 4 & 0,785127 & 0,528049 & Đạt yêu cầu \\
\hline Sự hài lòng & $\mathrm{Y}$ & 3 & 0,817978 & 0,500277 & Đạt yêu cầu \\
\hline
\end{tabular}

Nguồn: Tính toán tù số liệu khảo sát

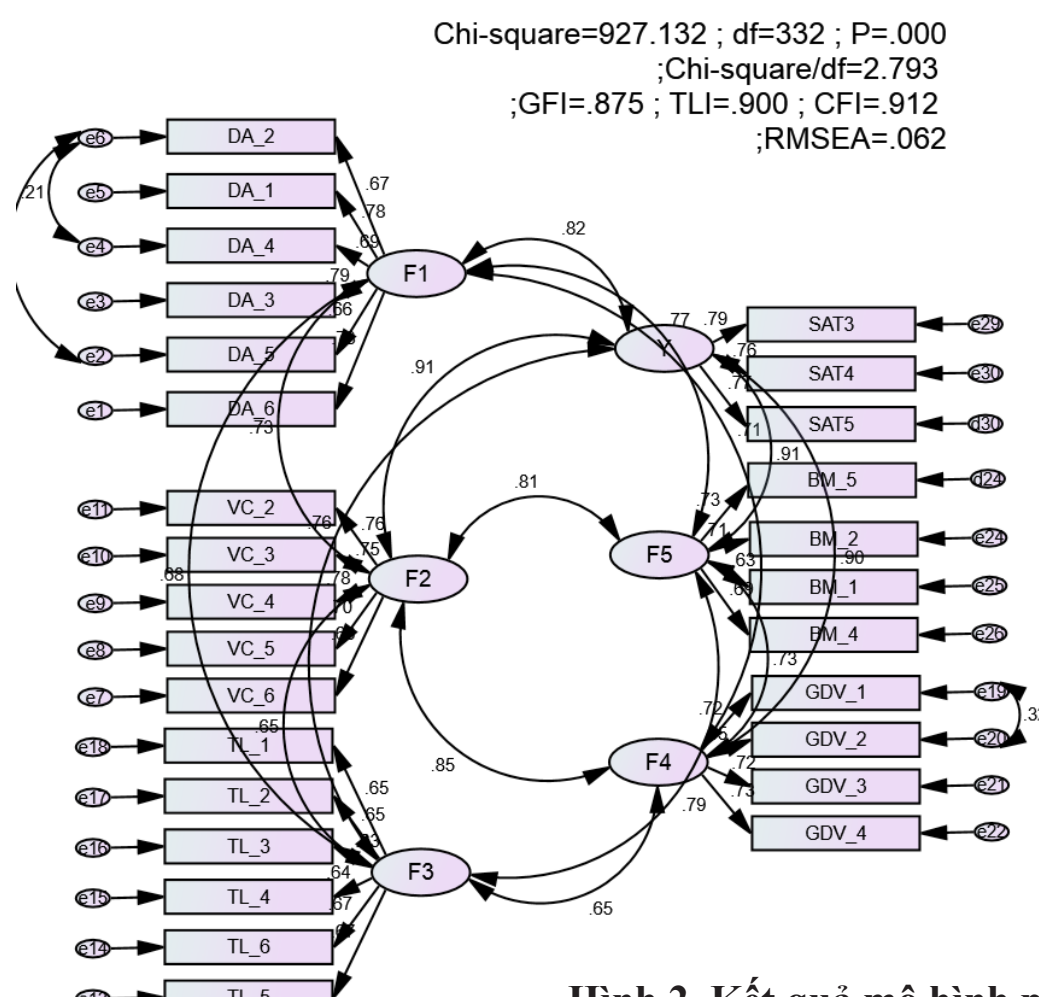

Hình 2. Kết quả mô hình phân tích CFA chuẩn hóa

Nguồn: Tính toán tì̀ số liệu khảo sát 
Hệ số tổng hợp $(\mathrm{CR})$ và phương sai trích bình quân (AVE): Áp dụng công thức tính $\mathrm{CR}$ và $A V E$ cho kết quả ở Bảng 7 . Kết quả nghiên cứu cho thấy các thang đo đều đạt yêu cầu về độ tin cậy và phương sai trích.

\subsection{Phân tích mô hình cấu trúc tuyến tính (SEM)}

Kết quả phân tích mô hình SEM cho thấy mô hình nghiên cứu phù hợp với dữ liệu thị trường: Chisquare $=845,819 ;$ df $=306 ; p=0,000$; $\mathrm{CMIN} / \mathrm{df}=2,764 ; \mathrm{GFI}=0,881 ; \mathrm{TLI}=0,904$; $\mathrm{CFI}=0,916 ;$ RMSEA $=0,062($ xem hình 3$)$.

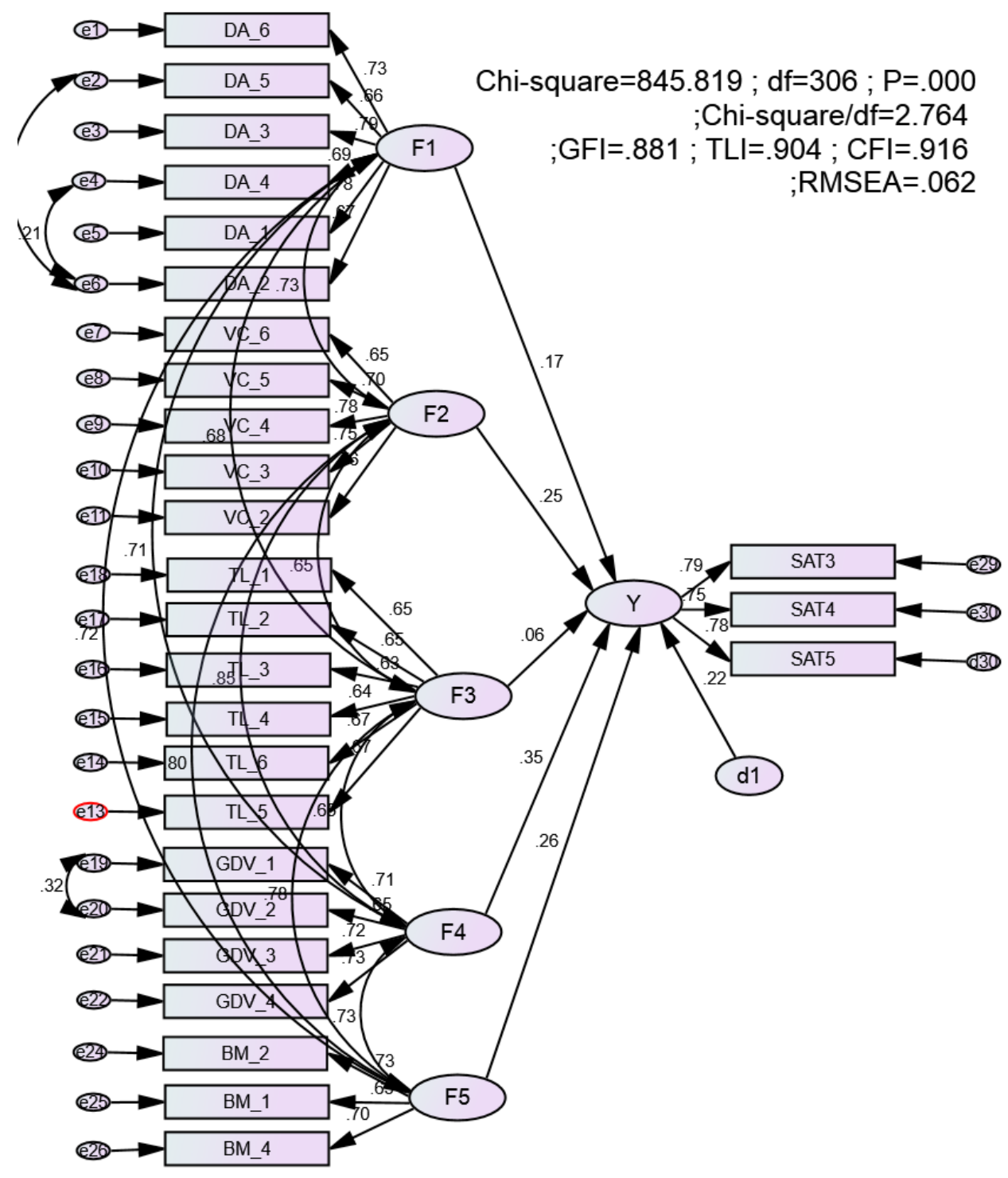

Hình 3. Kết quả mô hình SEM chuẩn hóa

Nguồn: Tính toán tù số liệu khảo sát

Kết quả kiểm định ở Bảng 8 cho thấy có 04 giả thuyết nghiên cứu được chấp nhận ở mức $\mathrm{P}<10 \%$, giả thuyết $\mathrm{H}_{3}$ bị bác bỏ. Mặt khác, kết quả kiểm định Boostrap với $\mathrm{N}=1000$ cho thấy mức độ sai lệch khá thấp, chứng tỏ càng kết quả từ mô hình SEM đáng tin cậy (Bảng 9). 
Bảng 8. Các hệ số từ mô hình cấu trúc tuyến tính

\begin{tabular}{|l|c|c|c|c|l|}
\hline \multicolumn{1}{|c|}{ Mối quan hệ } & Hệ số & S.E. & C.R. & $\mathbf{P}$ & \multicolumn{1}{|c|}{ Kết luận } \\
\hline $\mathrm{Y}<---\mathrm{F}_{1}$ & 0,172 & 0,056 & 3,056 & 0,002 & Chấp nhận giả thuyết $\mathrm{H}_{1}$ \\
\hline $\mathrm{Y}<---\mathrm{F}_{2}$ & 0,282 & 0,115 & 2,461 & 0,014 & Chấp nhận giả thuyết $\mathrm{H}_{2}$ \\
\hline $\mathrm{Y}<---\mathrm{F}_{3}$ & 0,074 & 0,089 & 0,828 & 0,408 & Bác bỏ giả thuyết $\mathrm{H}_{3}$ \\
\hline $\mathrm{Y}<---\mathrm{F}_{4}$ & 0,388 & 0,102 & 3,811 & 0,000 & Chấp nhận giả thuyết $\mathrm{H}_{4}$ \\
\hline $\mathrm{Y}<---\mathrm{F}_{5}$ & 0,305 & 0,114 & 2,679 & 0,007 & Chấp nhận giả thuyết $\mathrm{H}_{5}$ \\
\hline
\end{tabular}

Nguồn: Tính toán tù số liệu khảo sát

Bảng 9. Kết quả ước lượng bằng boostrap $(\mathrm{N}=1000)$

\begin{tabular}{|c|c|c|c|c|c|}
\hline Mối quan hệ & SE & SE-SE & Mean & Bias & SE-Bias \\
\hline $\mathrm{Y}<---\mathrm{F}_{1}$ & 0,073 & 0,002 & 0,167 & $-0,005$ & 0,002 \\
\hline $\mathrm{Y}<---\mathrm{F}_{2}$ & 0,168 & 0,004 & 0,269 & $-0,013$ & 0,005 \\
\hline $\mathrm{Y}<---\mathrm{F}_{3}$ & 0,128 & 0,003 & 0,067 & $-0,006$ & 0,004 \\
\hline $\mathrm{Y}<---\mathrm{F}_{4}$ & 0,134 & 0,003 & 0,395 & 0,008 & 0,004 \\
\hline $\mathrm{Y}<---\mathrm{F}_{5}$ & 0,191 & 0,004 & 0,329 & 0,024 & 0,006 \\
\hline
\end{tabular}

Nguồn: Tính toán tì̀ số liệu khảo sát

\subsection{Thảo luận kết quả nghiên cứu}

Kết quả kiểm định mô hình các nhân tố tác động đến sự hài lòng khách hàng tại các ngân hàng thương mại tỉnh Quảng Nam cho thấy có 04 nhân tố thật sự tác động đến sự hài lòng khách hàng. Kết quả này đồng nhất với nghiên cứu của Bhat et al. (2018), Colm et al. (2017), Janahi và Al Mubarak (2017), và Tadic et al. (2018).

Kết quả nghiên cứu cho thấy yếu tố năng lực đáp ứng các tác động dương tới sự hài lòng của khách hàng. Các nghiên cứu trên thế giới chứng minh rằng sự tận tâm và đồng cảm của nhân viên khiến khách hàng hài lòng (Yang, 2018; Zerva, Tsantopoulos, Grigoroudis, \& Arabatzis, 2018), vì sự tận tâm của nhân viên giúp khách hàng thỏa mãn nhu cầu nhanh hơn và an toàn hơn (Hjortskov, 2019; Newlin, McCall, Ottmar, Welch, \& Khairat, 2018).

Nghiên cứu này cho thấy yếu tố cơ sở vật chất có tác động đến sự hài lòng của khách hàng. Theo Yilmaz, Ari, và Gürbüz (2018) thì yếu tố cơ sở vật chất chính là yếu tố cấu thành nên chất lượng dịch vụ của doanh nghiệp, do đó chất lượng dịch vụ tăng sẽ khiến cải thiện sự hài lòng của khách hàng. Nhận định này phù hợp với nghiên cứu của Ling et al. (2016b) và Raza et al. (2015).

Trong nghiên cứu này, giá dịch vụ được cấu thành từ các biến quan sát như lãi suất, phí chuyển tiền, chính sách lãi suất. Giá dịch vụ có tác động cùng chiều đến sự hài lòng của khách hàng. Các nghiên cứu của Yen et al. (2018) và Hoàng Phương Dũng (2018) cũng cho kết luận tương tự.

Yếu tố bảo mật thông tin có tác động cùng chiều đến sự hài lòng của khách hàng. Janahi và Al Mubarak (2017) giải thích rằng yếu tố bảo mật thông tin giúp khách hàng cảm thấy an tâm và tự tin khi giao dịch tại ngân hàng. Nghiên cứu của Tadic et al. (2018) cũng cho kết luận tương tự.

\section{Kết luận và hàm ý quản trị}

Hiện nay, ngành ngân hàng đang chịu sự cạnh tranh rất khốc liệt. Do đó để nâng cao cạnh tranh, tăng thị phần, nâng cao lợi nhuận đòi hỏi ngân hàng phải có giải pháp nâng cao sự hài lòng của khách hàng. Vì thế, nghiên cứu này nhằm mục đích đo lường các nhân tố tác động tới sự hài lòng của khách hàng tại các 
ngân hàng thương mại. Để đạt được các mục tiêu nghiên cứu đề ra, quy trình nghiên cứu bao gồm: (1) Tổng hợp các lý thuyết và các nghiên cứu trước để đề xuất mô hình nghiên cứu; (2) đề tài áp dụng phương pháp nghiên cứu định tính nhằm hoàn thiện thang đo, và xây dựng bảng khảo sát; (3) nghiên cứu tiến hành khảo sát 461 khách hàng đã và đang giao dịch tại các ngân hàng thương mại tại tỉnh Quảng Nam, việc phân tích được thực hiện với các kỹ thuật như thống kê mô tả, kiểm định Cronbach's Alpha, phân tích nhân tố khám phá (EFA), phân tích nhân tố khẳng định (CFA), phân tích mô hình cấu trúc tuyến tính (SEM), kiểm định Bootstrap thông qua phần mềm SPSS 16 và Amos 22. Kết quả nghiên cứu của đề tài cho thấy có 04 nhân tố tác động đến sự hài lòng của khách hàng, gồm: "Năng lực đáp ứng", "Giá dịch vụ", "Bảo mật thông tin", "Cơ sở vật chất”.

Dựa vào kết quả nghiên cứu, nhóm nghiên cứu đề xuất một số hàm ý quản trị như sau:

- Cải thiện khả năng phục vụ khách hàng: Theo kết quả nghiên cứu, các biến quan sát của nhân tố năng lực phục vụ có điểm trung bình từ 3,45 đến 4,07 . Do đó, một số hàm ý quản trị đối với nhân tố này như sau: (1) Các nhân viên cần thay đổi tác phong giao dịch phục vụ khách hàng, đặc biệt đối với bộ phận làm việc trực tiếp với khách hàng; (2) cần xây dựng môi trường làm việc chuyên nghiệp, và văn minh; (3) Tăng cường sự hợp tác giữa các bộ phận để giải quyết các nhu cầu của khách hàng nhanh nhất.

- Cải thiện tình hình cơ sở vật chất cho ngân hàng: Điểm trung bình của biến quan sát cấu thành nhân tố cơ sở vật chất có điểm trung bình từ 3,25 (biến "hệ thống quản trị mạng tốt") đến 4,27 (biến "hệ thống ATM đạt yêu cầu"). Do đó, nghiên cứu đề xuất: (1) Nâng cao vai trò quản trị mạng; (2) quản trị hệ thống thông tin để hạn chế rủi ro cho khách hàng và ngân hàng, chú ý đầu tư phát triển công nghệ và nâng cấp hệ thống máy rút tiền tự động (ATM).

- Cải thiện giá dịch vụ: Nhân tố giá dịch vụ có 2 biến quan sát có điểm trung bình thấp nhất là "lãi suất cạnh tranh" (điểm trung bình 3,23) và "phí chuyển tiền thấp" (điểm trung bình $3,17)$. Do đó, nghiên cứu đề xuất: (1) Lãi suất cần điều chỉnh linh hoạt nhằm tạo điều kiện cho khách hàng và nâng cao hiệu quả kinh doanh cho ngân hàng; (2) áp dụng lãi suất linh hoạt cho khách hàng có nguồn tiền gửi lớn, giảm bớt các thủ tục hành chính không cần thiết, duy trì khách hàng VIP thông qua các chương trình quà tặng lớn.

- Cải thiện tính bảo mật thông tin: Nhân tố bảo mật thông tin có 2 biến quan sát có điểm trung bình khá thấp gồm biến "hệ thống bảo mật khá hiện đại" (3,99 điểm) và biến "mức độ rủi ro thấp" (4,03 điểm). Do đó, nghiên cứu đề xuất nên áp dụng hệ thống quản lý ISO trong các quy trình nghiệp vụ để hạn chế rủi ro, phân quyền và hạn mức kinh doanh cho từng bộ phận, tăng cường công tác thanh kiểm tra.

Bên cạnh những kết quả đạt được, một số hạn chế dưới đây cần các nghiên cứu sau cải thiện: (1) Phương pháp lấy mẫu thuận tiện làm cho mẫu khảo sát có tính tổng quát chưa cao, do đó sai số khảo sát còn có sai số; (2) Nghiên cứu này chỉ thực hiện tại tỉnh Quảng Nam, do đó các nghiên cứu tiếp theo nên mở rộng địa bàn nghiên cứu để xem xét sự khác biệt về sự hài lòng khách hàng tại các ngân hàng có quy mô khác nhau.

\section{Tài liệu tham khảo}

\section{Tiếng Việt}

Lê Thị Thanh Giang. (2016). Các yếu tố ảnh hương đến sự hài lòng khách hàng về chất lương dịch vu tín dụng cá nhân tại ngân hàng Techcombank Cần Tho. Đại học Tây Đô, Retrieved from http://115.74.210.103:81/tailieuso/handle/123456789/185

Trần Dục Thức và Phạm Thị Lan Hương. (2017). Các yếu tố tác động đến sụ hài lòng của khách hàng đối với dịch vu thẻ ATM tại Ngân hàng TMCP Ngoại thương Việt Nam. (Master), Trường Đại học Bà RịaVũng Tàu. Viện Du lịch-Quản lý-Kinh doanh, Hà Nội. 
Trần Thu Hằng. (2017). Báo cáo ngành ngân hàng 2017. Retrieved from https://vcbs.com.vn/vn/ Communication/GetReport?reportId $=4824$

Trần Trọng Khuê và Lê Thúy Kiều. (2017). Các yếu tố ảnh hưởng đến sự hài lòng của khách hàng về chất luợng dịch vu ngân hàng bán lẻ tại ngân hàng TMCP Đầu tu và Phát triển Việt Nam-Chi nhánh Phú $M \tilde{y}$. Trường Đại học Bà Rịa-Vũng Tàu. Viện Du lịch-Quản lý-Kinh doanh, Retrieved from http:// thuvienso.bvu.edu.vn/handle/TVDHBRVT/16208

\section{Tiếng Anh}

Adeel, A., Ali, R., \& Pengcheng, Z. (2018). Network centrality and individual creativity: A mediated moderation of knowledge integration with network cost. Pakistan Journal of Commerce and Social Sciences (PJCSS), 12(3), 983-1007.

Amin, M. (2016). Internet banking service quality and its implication on e-customer satisfaction and e-customer loyalty. International journal of bank marketing, 34(3), 280-306.

Anouze, A. (2019). Customer satisfaction and its measurement in Islamic banking sector: a revisit and update. Journal of Islamic Marketing, 10(2), 565-588. Retrieved from https://doi.org/10.1108/JIMA07-2017-0080.

Belás, J., Chocholáková, A., \& Gabčová, L. (2015). Satisfaction and loyalty of banking customers: a gender approach. Economics and Sociology, 8(1), 176-188.

Belás, J., Korauš, M., Kombo, F., \& Korauš, A. (2016). Electronic banking security and customer satisfaction in commercial banks. Journal of security and sustainability issues, 5(3), 411-422.

Bhat, S. A., Darzi, M. A., \& Parrey, S. H. (2018). Antecedents of Customer Loyalty in Banking Sector: A Mediational Study. Vikalpa, 43(2), 92-105. doi:https://doi.org/10.1177\%2F0256090918774697

Chatfield, C. (2018). Introduction to multivariate analysis: Routledge.

Colm, L., Ordanini, A., \& Parasuraman, A. (2017). When service customers do not consume in isolation: A typology of customer copresence influence modes (CCIMs). Journal of Service Research, 20(3), 223-239.

Darzi Mushtaq, A. (2018). Personnel capability and customer satisfaction as predictors of customer retention in the banking sector: A mediated-moderation study. International journal of bank marketing, 36(4), 663-679. Retrieved from https://doi.org/10.1108/IJBM-04-2017-0074.

Dsouza, R. S., Subhash, K. B., Chen, R. F.,, \& Weiermair, K. (2018). Service quality and customer satisfaction: An empirical analysis of banking sector in Goa. International Journal of Banking, Risk and Insurance, 6(2), 1-22.

Fabrigar, L. R., \& Wegener, D. T. (2011). Exploratory factor analysis: Oxford University Press.

Firdous, S., \& Farooqi, R. (2017). Impact of internet banking service quality on customer satisfaction. The Journal of Internet Banking and Commerce, 22(1), 1-17.

Hair, J. F., Black, W. C., Babin, B. J., Anderson, R. E., \& Tatham, R. L. (2006). Multivariate data analysis (Vol. 6). In: Upper Saddle River, NJ: Pearson Prentice Hall.

Hair Jr, J. F., Hult, G. T. M., Ringle, C., \& Sarstedt, M. (2016). A primer on partial least squares structural equation modeling (PLS-SEM): Sage Publications.

Hammoud, J., Bizri, R. M., \& El Baba, I. (2018). The Impact of E-Banking Service Quality on Customer Satisfaction: Evidence From the Lebanese Banking Sector. SAGE Open, 8(3). doi:https://doi. org $10.1177 \% 2 \mathrm{~F} 2158244018790633$

Hill, N., \& Alexander, J. (2017). The handbook of customer satisfaction and loyalty measurement: Routledge.

Hjortskov, M. (2019). Citizen expectations and satisfaction over time: Findings from a large sample panel survey of public school parents in Denmark. The American Review of Public Administration, 49(3), 353-371.

Hult, G. T. M., Morgeson, F. V., Morgan, N. A., Mithas, S., \& Fornell, C. (2017). Do managers know what their customers think and why? Journal of the Academy of Marketing Science, 45(1), 37-54.

Jalali, M. S., Ferreira, F. A. F., Ferreira, J. J. M., \& Meidute, I. (2016). Integrating metacognitive and psychometric decision-making approaches for bank customer loyalty measurement. International Journal of Information Technology \& Decision Making, 15(04), 815-837.

Janahi, M. A., \& Al Mubarak, M. M. S. (2017). The impact of customer service quality on customer satisfaction in Islamic banking. Journal of Islamic Marketing, 8(4), 595-604. doi:https://doi.org/10.1108/JIMA07-2015-0049

Koraus, A., Stefko, R., \& Dobrovic, J. (2016). Decision-making satisfaction and behaviour of bank customers: Survey results analysis. Aktual'ni Problemy Ekonomiky (Actual Problems in Economics), 5(186), 291-301. 
Larivière, B., Keiningham, T. L., Aksoy, L., Yalçin, A., Morgeson III, F. V., \& Mithas, S. (2016). Modeling heterogeneity in the satisfaction, loyalty intention, and shareholder value linkage: a cross-industry analysis at the customer and firm levels. Journal of Marketing Research, 53(1), 91-109.

Ling, G. M., Fern, Y. S., Boon, L. K., \& Huat, T. S. (2016a). Understanding customer satisfaction of internet banking: A case study in Malacca. Procedia Economics and Finance, 37, 80-85.

Ling, G. M., Fern, Y. S., Boon, L. K., \& Huat, T. S. (2016b). Understanding customer satisfaction of internet banking: A case study in Malacca. Procedia Economics and Finance, 37(4), 80-85.

Lone, F. A., Aldawood, E., \& Bhat, U. (2017). Comparative Analysis of Customer Satisfaction towards Islamic and Conventional Banking: An Empirical Study from Saudi Arabia. 7(1), 273-280. doi:https:// ssrn.com/abstract $=2918680$

Mohan, M. R., John, S. F., Bhati, A., Bansal, A., Ashok, B., Kumar, N., \& AN, J. (2016). E-Banking Services and Customer Satisfaction in Dindugal District-An Empirical Study. Journal of Exclusive Management Science, 5(1), 1-5.

Newlin, T., McCall, T., Ottmar, P., Welch, B., \& Khairat, S. (2018). Assessing the Satisfaction of Citizens Using Teleconsent in Clinical Research. Studies in health technology and informatics, 247, 685-689.

Ong, K. S., Nguyen, B., \& Syed Alwi, S. F. (2017). Consumer-based virtual brand personality (CBVBP), customer satisfaction and brand loyalty in the online banking industry. International journal of bank marketing, 35(3), 370-390.

Pérez, A., \& Del Bosque, I. R. (2015). Corporate social responsibility and customer loyalty: exploring the role of identification, satisfaction and type of company. Journal of Services Marketing, 29(1), 15-25.

Rajagopal, K., \& Mahajan, V. (2019). Service Quality Gap Analysis in the Indian Banking Sector-"A Customer Perspective Review.". International Journal of Human Resource Management and Research (IJHRMR), 9(3), 1-8.

Raza, S. A., Jawaid, S. T., \& Hassan, A. (2015). Internet banking and customer satisfaction in Pakistan. Qualitative Research in Financial Markets, 7(1), 24-36.

Saleem, M. A., Zahra, S., Ahmad, R., \& Ismail, H. (2016). Predictors of customer loyalty in the Pakistani banking industry: a moderated-mediation study. International journal of bank marketing, 34(3), 411430.

Sayani, H. (2015). Customer satisfaction and loyalty in the United Arab Emirates banking industry. International journal of bank marketing, 33(3), 351-375.

Shahrinaz, I., Kasuma, J., Naim, A. S. A., Rahim, E. A., Arabi, A., Ismawi, N., \& Rosli, R. (2017). Determinant of customers' preference in selecting Islamic banks. International Journal of Advanced and Applied Sciences, 4(3), 117-121.

Silverman, B. W. (2018). Density estimation for statistics and data analysis: Routledge.

Singhal, N., Bala, K., \& Sarawgi, S. (2018). An empirical study of employee engagement and customer satisfaction in banking sector. Journal of Business Thought, 8(2), 24-41. Retrieved from http:// informaticsjournals.com/index.php/jbt/article/view/21198.

Tadic, D., Aleksic, A., Mimovic, P., Puskaric, H., \& Misita, M. (2018). A model for evaluation of customer satisfaction with banking service quality in an uncertain environment. Total Quality Management \& Business Excellence, 29(11-12), 1342-1361. doi:https://doi.org/10.1080/14783363.2016.1257905

Varmuza, K. (2018). Methods for Multivariate Data Analysis (Vol. 399). Canada: Wiley Publishing.

Yang, Y. (2018). Is transparency a double-edged sword in citizen satisfaction with public service? Evidence from China's public healthcare. Journal of Service Theory and Practice, 28(4), 484-506.

Yen, Y. Y., Hui, D. G. M., Jais, M., \& Rasiah, D. A. (2018). Determinants of Customer Loyalty in Banking Industry. Advanced Science Letters, 24(5), 3026-3030. doi:https://doi.org/10.1166/asl.2018.11312

Yilmaz, V., Ari, E., \& Gürbüz, H. (2018). Investigating the relationship between service quality dimensions, customer satisfaction and loyalty in Turkish banking sector: an application of structural equation model. International journal of bank marketing, 36(3), 423-440.

Youssef, M. A., Anadol, Y., \& Zahrani, A. A. (2017). Modelling customer's intention to use e-banking in Saudi Arabia: an empirical study. International Journal of Business Innovation and Research, 14(2), 239-258.

Zerva, A., Tsantopoulos, G., Grigoroudis, E., \& Arabatzis, G. (2018). Perceived citizens' satisfaction with climate change stakeholders using a multicriteria decision analysis approach. Environmental Science \& Policy, 82, 60-70. 